\title{
Polymyalgia rheumatica following infective triggers or vaccinations: a different subset of disease?
}

\author{
Paolo Falsetti ${ }^{1}$, Edoardo Conticini ${ }^{1}$, Caterina Acciai ${ }^{2}$, Caterina Baldi ${ }^{1}$, Marco Bardelli ${ }^{1}$, \\ Stefano Gentileschi ${ }^{1}$, Luca Cantarini ${ }^{1}$, Bruno Frediani ${ }^{1}$ \\ ${ }^{1}$ Rheumatology Unit, University of Siena, Italy \\ ${ }^{2}$ Neurorehabilitation Unit, Arezzo Hospital, Italy
}

\begin{abstract}
Objectives: Polymyalgia rheumatica (PMR) is the commonest inflammatory disorder of the elderly; an association with environmental triggers and a deregulated immune response have been described. The aim of this study was to investigate the association of environmental triggers before the onset of PMR.

Material and methods: The database of 58 consecutive PMR patients recruited from a single rheumatology secondary care setting was retrospectively analyzed to investigate the frequency of environmental triggers and correlations with clinical characteristics, ultrasound and laboratory data.

Results: Fifteen PMR patients (26\%) described a connection with environmental agents: six PMR patients reported a vaccination, 4 reported a respiratory tract infection, 5 reported seasonal influenza before the onset of the disease. The model of multivariate linear regression which better predicted a shorter time to normalize inflammatory reactants $\left(R^{2}=27.46 \%, p=0.0042\right)$ comprised the presence of an environmental trigger and a higher PCR. A linear regression analysis confirmed an inverse correlation between $P C R$ at onset and time to normalize inflammatory reactant $(r=-0.3031, p=0.0208)$. A significant correlation was demonstrated between presence of environmental trigger and shorter time to normalize inflammation ( $r=-0.5215, p<0.0001)$, and lesser frequency of gleno-humeral synovitis on US $(r=-0.3774$, $p=0.0038)$.

Conclusions: Our work describes a correlation between environmental triggers in PMR and higher CRP at diagnosis, faster response to therapy, and milder shoulder synovitis. We may suppose that these patients belong to a more specific subtype of PMR, in whom external stimuli, such as vaccination or infection, may lead to a deregulated response within the context of an impaired senescent immuno-endocrine system.
\end{abstract}

Key words: polymyalgia rheumatica, infection, vaccination, ultrasound.

\section{Introduction}

Polymyalgia rheumatica (PMR) is a common condition characterized by inflammatory pain and stiffness in the shoulder and in the pelvic girdle and neck. It occurs in people over the age of 50, and is associated with an acute-phase response, a rapid response to low doses of glucocorticoids (GC), and a favorable prognosis. Giant cell arteritis (GCA) is a large vessel vasculitis associated with PMR in about half of cases, suggesting that the two disease could be different or progressive aspects of the same disease.

Previous studies reported an increased risk of infections before PMR and GCA [1-3] and other studies analyzed specific infective triggers (e.g. herpes virus) for GCA/PMR [1, 4].

Moreover, there are case reports of subjects who developed PMR following influenza vaccination $[3,5,6]$. 
Vaccine components, such as adjuvants, can activate the immune system and induce inflammatory manifestations (also defined as autoimmune/inflammatory syndrome induced by adjuvants).

In both cases, different biological mechanisms have been proposed to explain the link between infective agents or vaccinations and development of GCA/PMR Preexisting immune system alteration due to genetic polymorphisms could increase the deregulated inflammatory response. Moreover, immune senescence has been described as adaptive and innate immune deregulation in the elderly, with excessive and prolonged production of pro-inflammatory cytokines $[7,8]$. In the elderly, also a relative deficit of activation in the hypothalamic-pituitary-adrenal (HPA) axis could be responsible for a deregulated response to environmental stresses [9-11].

The aim of this study was to investigate the frequency of environmental triggers before the onset of PMR and the association between presence of triggers and clinical characteristics using a retrospective cohort study within a secondary care database.

\section{Material and methods}

In order to define the association of PMR with infections or vaccines as environmental triggers of the disease, we retrospectively analyzed the database of 58 PMR patients consecutively recruited from a single rheumatology secondary care setting between January 2003 and December 2017. All the PMR patients satisfied the Bird criteria (until 2012) [12] and 2012 ACR/EULAR criteria (beyond 2013) [13] and were followed for at least 24 months, with essentially the same diagnostic and management modalities reported in a previous work [3].

The patients were all referred to a rheumatologist by general practitioners, who agreed to refer suspected PMR cases prior to GC therapy, with basal laboratory tests: erythrocyte sedimentation rate (ESR), C-reactive protein (CRP), serum electrophoresis, rheumatoid factor $(R F)$, anticyclic citrullinated peptide antibodies (ACPA Abs), antinuclear antibodies (ANA), creatine kinase (CK), complete blood count, renal and liver function, serum urate, and urinalysis. Exclusion criteria were prior steroid therapy or preexisting mimicking diseases. X-rays of the hand and foot were obtained, to exclude signs of erosive arthritis and/or chondrocalcinosis. Some further investigations (e.g. thorax radiography, abdomen US) were carried out when necessary.

At the first visit, patients underwent routine multidistrict ultrasound (US) examination of both proximal (shoulder, hip) and distal sites regardless of the presence of signs or symptoms of inflammatory involvement, with a SonoSite (Bothell, USA) Titan with a multifrequency linear 5-10 MHz probe (until 2015) and an Esaote (Genova, Italy) MyLab Gamma with multifrequency linear 6-13 $\mathrm{MHz}$ probe (after 2015). Each synovitis was scored as 0 (absent), 1 (mild), or 2 (significant) and for statistical purposes the higher score for each site was recorded.

The glucocorticoid therapy scheme followed previous recommendations, with a initial daily dose of $16 \mathrm{mg}$ methylprednisolone (20 mg prednisone equivalent daily), whereas in patients with relevant comorbidities (in particular diabetes, glaucoma), a lower dose was preferred [14]. The initial dose was maintained for 10-15 days, then tapered to $12 \mathrm{mg}$ for 15-20 days, to reach a daily dose of $8 \mathrm{mg}$ within 4-8 weeks, and then $4 \mathrm{mg}$ for another 4-8 weeks. Once remission was achieved the dose was tapered under $4 \mathrm{mg}$ by $1 \mathrm{mg}$ every 4 weeks until discontinuation given that remission was maintained.

Laboratory tests were generally repeated after a month from the first visit (when corticosteroid therapy was started) and about every three months in the follow-up. For each patient information on gender, age, systemic symptoms, and possible environmental triggers, was collected. In particular, the possible environmental trigger was recorded if it occurred within three months from onset of polymyalgic symptoms and if the patient him- or herself judged this event as correlated to his or her symptoms. For each case we also defined the time (in months) to normalization of inflammatory reactants. We defined dependency on GC when a dose of GC (equal or less than $4 \mathrm{mg}$ methylprednisolone, or $5 \mathrm{mg}$ prednisone equivalent daily) remained necessary to avoid myalgic symptoms, despite a persistent remission of inflammatory reactants and absence of synovitis on US.

Statistical analysis was performed using the GraphPad InStat 3 package (GraphPad Software Inc, La Jolla, CA, USA). Multivariate and univariate linear regression analysis was applied to test the effects of variables on outcome and to define its correlation. The non-parametric Spearman rank test was applied to correlate variables. The two-tailed unpaired $t$-test was used to compare means between the two groups, whereas Fisher's exact test was used to compare the percentages between the two groups for categorical variables. The level of statistical significance was set at a p-level of 0.05 .

\section{Results}

Median age at the time of diagnosis was 71 years (range 63-89) and 60\% were female (35 females, 23 males). Median ESR and CRP were $51 \mathrm{~mm} / \mathrm{h}$ (range 6-99, normal value $<21$ ) and $3 \mathrm{mg} / \mathrm{dl}$ (range 0.5-1.3, normal value $<0.5)$ respectively. The mean time to normalize 
the inflammatory reactant was 6.9 months (range 4-12) (Table I).

Fifteen patients (26\%) with PMR described a connection with environmental agents: six PMR patients reported a vaccination before the onset of disease (4 with influenza vaccine, 2 with tetanus toxoid vaccine); 3 reported an upper respiratory tract infection and 1 lower respiratory tract infection (pneumonia) before the onset of disease. Five patients reported seasonal influenza as a trigger of its PMR. In three patient a concurrent GCA was suspected, but none of these reported an environmental trigger.

The model of multivariate linear regression which better predicted a shorter time to normalize inflammatory reactant ( $\left.R^{2} 27.46 \%, p=0.0042\right)$ comprised the presence of an environmental trigger and a higher CRP. A linear regression analysis confirmed an inverse correlation between CRP at onset and time to normalize the inflammatory reactant $(r=-0.3031, p=0.0208)$. Spearman rank test between variables demonstrated a significant correlation between presence of an environmental trigger and shorter time to normalize inflammation $(r=-0.5215, p<0.0001)$, and lower frequency of gle- no-humeral synovitis on US $(r=-0.3774, p=0.0038)$. The results were confirmed by comparison of means between the two groups (Table I).

The presence of an environmental trigger failed to demonstrate correlations with ESR at diagnosis, fever, systemic symptoms, hip synovitis, subacromial-subdeltoid bursitis, long head of biceps tendon tenosynovitis or distal synovitis on US examination, gender and age (Table I).

In 10 patients who reported an environmental trigger before the onset of PMR, a very low dose of GC remained necessary to avoid myalgic symptoms, despite a persistent remission of inflammatory reactants and absence of synovitis on US; this aspect appeared significantly more frequent in the group with an environmental trigger $(p=0.0398$, Table I). No cases of GCA were suspected in these patients during the follow-up.

\section{Discussion}

Even if a few studies did not demonstrate a seasonal pattern or association with infections in PMR and GCA $[15,16]$, the association between PMR and influenza vac-

Table I. Demographic, laboratory, and ultrasonographic characteristics of patients with polymyalgia rheumatica, and subgroups with or without environmental trigger before disease onset

\begin{tabular}{|c|c|c|c|c|}
\hline Characteristics & Total & PMR with trigger & PMR without trigger & $p$ (test) \\
\hline $\begin{array}{l}\text { PMR patients (females/ } \\
\text { males) }\end{array}$ & $58(35 / 23)$ & $15(9 / 6)$ & $43(26 / 17)$ & $\begin{array}{c}0.99-\mathrm{ns} \\
\text { (two-sided Fisher's exact test) }\end{array}$ \\
\hline $\begin{array}{l}\text { Age, years (range) } \\
\text { SD }\end{array}$ & $\begin{array}{c}71(63-89) \\
7.16\end{array}$ & $\begin{array}{c}74.6(66-86) \\
6.98\end{array}$ & $\begin{array}{l}70.8(63-89) \\
\text { SD } 6.81\end{array}$ & $\begin{array}{c}0.0697-\mathrm{ns} \\
\text { (unpaired } t \text {-test) }\end{array}$ \\
\hline $\begin{array}{l}\text { Mean ESR at onset (range) } \\
\text { SD }\end{array}$ & $\begin{array}{c}51 \mathrm{~mm} / \mathrm{h}(6-99) \\
21.18\end{array}$ & $\begin{array}{c}59 \mathrm{~mm} / \mathrm{h} \\
\text { (24-83) SD } 19.51\end{array}$ & $\begin{array}{c}49 \mathrm{~mm} / \mathrm{h} \\
(6-99) \mathrm{SD} 21.01\end{array}$ & $\begin{array}{c}0.1119-\mathrm{ns} \\
\text { (unpaired } t \text {-test) }\end{array}$ \\
\hline $\begin{array}{l}\text { Mean CRP at onset (range) } \\
\text { SD }\end{array}$ & $\begin{array}{c}3 \mathrm{mg} / \mathrm{dl}(0.5-11.3) \\
5.94\end{array}$ & $\begin{array}{c}6.8 \mathrm{mg} / \mathrm{dl}(2.3-11.3) \\
2.62\end{array}$ & $\begin{array}{c}2.4 \mathrm{mg} / \mathrm{dl}(0.5-7.8) \\
6.29\end{array}$ & $\begin{array}{c}0.0113^{*} \\
\text { (unpaired } t \text {-test) }\end{array}$ \\
\hline $\begin{array}{l}\text { Disease duration, months } \\
\text { SD }\end{array}$ & $\begin{array}{l}6.9 \\
2.72\end{array}$ & $\begin{array}{l}4.8 \\
1.27\end{array}$ & $\begin{array}{l}7.6 \\
2.82\end{array}$ & $\begin{array}{c}0.0005^{\star *} \\
\text { (unpaired } t \text {-test) }\end{array}$ \\
\hline $\begin{array}{l}\text { GC dependence } \\
\text { (see text for definition) }\end{array}$ & $25 / 58$ & $10 / 15$ & $15 / 43$ & $\begin{array}{c}0.0398^{*} \\
\text { (two-sided Fisher's exact test) }\end{array}$ \\
\hline $\begin{array}{l}\text { US mean score shoulder: } \\
\text { GH (range) } \\
\text { SD }\end{array}$ & $\begin{array}{l}0.7(0-2) \\
0.86\end{array}$ & $\begin{array}{l}0.1(0-1) \\
\text { SD } 0.4\end{array}$ & $\begin{array}{l}0.9(0-2) \\
0.92\end{array}$ & $\begin{array}{c}0.0018^{* *} \\
\text { (unpaired } t \text {-test) }\end{array}$ \\
\hline $\begin{array}{l}\text { US mean score shoulder: } \\
\text { SA-SD (range) } \\
\text { SD }\end{array}$ & $\begin{array}{c}1.3(0-2) \\
0.87\end{array}$ & $\begin{array}{l}1.1(0-2) \\
\text { SD } 0.91\end{array}$ & $\begin{array}{c}1.4(0-2) \\
0.84\end{array}$ & $\begin{array}{c}0.2410-\mathrm{ns} \\
\text { (unpaired } t \text {-test) }\end{array}$ \\
\hline $\begin{array}{l}\text { US mean score shoulder: } \\
\text { LHBT (range) } \\
\text { SD }\end{array}$ & $\begin{array}{c}1.2(0-2) \\
0.83\end{array}$ & $\begin{array}{l}0.8(0-2) \\
\text { SD } 0.71\end{array}$ & $\begin{array}{c}1.3(0-2) \\
0.91\end{array}$ & $\begin{array}{c}0.0561-\mathrm{ns} \\
\text { (unpaired } t \text {-test) }\end{array}$ \\
\hline $\begin{array}{l}\text { US mean score hip (range) } \\
\text { SD }\end{array}$ & $\begin{array}{c}0.4(0-2) \\
0.82\end{array}$ & $\begin{array}{l}0.2(0-2) \\
\text { SD } 0.70\end{array}$ & $\begin{array}{c}0.6(0-2) \\
0.93\end{array}$ & $\begin{array}{c}0.1805-\mathrm{ns} \\
\text { (unpaired } t \text {-test) }\end{array}$ \\
\hline
\end{tabular}

$C R P$-C-reactive protein, ESR - erythrocyte sedimentation rate, GC - glucocorticoids, GH - gleno-humeral joint, LHBT - long head of biceps tendon, PMR - polymyalgia rheumatica, SA-SD - subacromial-subdeltoid bursa, SD - standard deviation, US - ultrasound, ${ }^{*} p<0.05,{ }^{* *} p<0.01$, ns - not significant. 
cination and/or infections is well known and reported in several case reports and case series [1-6]. Our data support these findings and provide the largest case series of PMR triggered by infection or vaccinations among an elderly population in south-eastern Tuscany. Considering the notably high number of years encompassed by our retrospective analysis, a direct correlation with any specific subtype of vaccine, which varies year per year, can be excluded.

In this study an environmental trigger was reported in almost a quarter of cases. These data suggest that PMR triggered by an environmental factor could constitute a different subset of milder disease, as they have a more rapid response to $\mathrm{GC}$ therapy with a higher CRP at diagnosis. Moreover, in these patients US could reveal lesser gleno-humeral synovitis. An inverse correlation between higher CRP at onset of PMR and impaired activation of HPA axis has been demonstrated [10]. Interestingly, a subset of PMR with similar clinical (higher CRP, faster response to glucocorticoids) and imaging characteristics (mainly extracapsular hip involvement detected with whole-body magnetic resonance) was recently described [17]. Moreover, those patients with an extracapsular pattern were less likely to be able to stop GC therapy within the first year [17].

Also in our case study $66 \%$ of patients with an environmental trigger showed significant difficulties to stop GC therapy. This aspect could suggest that in this subgroup of patients a previous HPA axis impairment could give a higher susceptibility to abnormal responses to stresses (polymyalgic phase) but also to a subsequent necessity of substitutive hormonal replacement (dependence on low GC doses) once remission is obtained.

Further studies could be useful to determine whether this subset of PMR patient should be reclassified as having definite immunological deregulation and HPA axis impairment, where low doses of GC constitute a substitutive hormonal therapy [9, 10]. A prodromal phase to musculoskeletal symptoms, with fatigue and sleep problems, has been previously described, and it could be consistent with this immune-endocrinologic deregulation [18].

Even if our retrospective data cannot provide information about the endocrinologic, immunological and genetic state of our PMR patients, our data support the hypothesis that an infective and immunological stimulus in an elderly patient can exert excessive and prolonged production of pro-inflammatory cytokines as described in the condition defined as immunosenescence, an adaptive and innate immune deregulation in the elderly $[7,8]$. These hypotheses are consistent with the findings of the recently published Danish population-based study, whose authors found a higher risk of infections before the development of PMR [1].

\section{Conclusions}

Our paper is the first one evidencing a strict correlation between CRP at diagnosis, response to therapy and environmental trigger. We may suppose that our patients belong to a more specific subtype of PMR, in whom external stimuli, such as vaccination or infection, may lead to an inappropriate response within the context of impaired immune and endocrine systems.

We recommend systematic research of previous infection or vaccination in patients with recent onset of PMR.

Despite important advances in the treatment of PMR and GCA, etiology remains an intriguing matter of debate. We hope that our findings will represent a new step forward in its comprehension, but further studies are needed.

The authors declare no conflict of interest.

\section{References}

1. Brault C, Riis AH, Mor A, et al. Does low risk of infections as a marker of effective immunity predict increased risk of subsequent giant cell arteritis or polymyalgia rheumatica? A Danish population-based case-control study. Clin Epidemiol 2018; 10: 1533-1543, DOI: 10.2147/CLEP.S158293.

2. Iwata K, Mizuno Y. A case of polymyalgia rheumatica following influenza B infection. Int J Gen Med 2015; 8: 345-347, DOI: 10.2147/IJGM.S92435

3. Falsetti P, Acciai C, Volpe A, Lenzi L. Ultrasonography in early assessment of elderly patients with polymyalgic symptoms: a role in predicting diagnostic outcome? Scand J Rheumatol 2011; 40: 57-63, DOI: 10.3109/03009742.2010.486766.

4. Rhee RL, Grayson PC, Merkel PA, Tomasson G. Infections and the risk of incident giant cell arteritis: a population-based, case-control study. Ann Rheum Dis 2017; 76: 1031-1035, DOI: 10.1136/annrheumdis-2016-210152.

5. Soriano A, Verrecchia E, Marinaro A, et al. Giant cell arteritis and polymyalgia rheumatica after influenza vaccination: report of 10 cases and review of the literature. Lupus 2012; 21 : 153-157, DOI: 10.1177/0961203311430222.

6. Siddiqi N, Gulati G, Ware AE. Polymyalgia Rheumatica and Autoimmune Inflammatory Syndrome Induced by Adjuvants Following Administration of Influenza Vaccine. J Clin Rheumatol 2018; 24: 410-412, DOI: 10.1097/RHU.0000000000000712.

7. Mohan SV, Liao YJ, Kim JW, et al. Giant cell arteritis: immune and vascular aging as disease risk factors. Arthritis Res Ther 2011; 13: 231. DOI: 10.1186/ar3358.

8. Watad A, Bragazzi NL, Adawi M, Amital H, Toubi E, Porat BS, et al. Autoimmunity in the Elderly: Insights from Basic Science and Clinics - A Mini-Review. Gerontology 2017; 63: 515-523, DOI: 10.1159/000478012. 
9. Cutolo M, Foppiani L, Minuto F. Hypothalamic-pituitaryadrenal axis impairment in the pathogenesis of rheumatoid arthritis and polymyalgia rheumatica. J Endocrinol Invest 2002; 25 (10 Suppl): 19-23.

10. Demir H, Tanriverdi F, Özoğul N, et al. Evaluation of the hypothalamic-pituitary-adrenal axis in untreated patients with polymyalgia rheumatica and healthy controls. Scand J Rheumatol 2006; 35: 217-223, DOI: 10.1080/03009740500474586.

11. Kniazkova I, Shapovalova L, Bogun M. A case report of polymyalgia rheumatica. Reumatologia 2018; 56: 190-193, DOI: 10.5114/reum.2018.76906.

12. Bird HA, Leeb BF, Montecucco CM, et al. A comparison of the sensitivity of diagnostic criteria for polymyalgia rheumatica. Ann Rheum Dis 2005; 64: 626-629, DOI: 10.1136/ ard.2004.025296

13. Dasgupta B, Cimmino MA, Maradit-Kremers H, et al. 2012 provisional classification criteria for polymyalgia rheumatica: a European League Against Rheumatism/American College of
Rheumatology collaborative initiative. Ann Rheum Dis 2012; 71: 484-492, DOI: 10.1136/annrheumdis-2011-200329.

14. Dejaco C, Singh YP, Perel P, et al. 2015 Recommendations for the management of polymyalgia rheumatica: a European League Against Rheumatism/American College of Rheumatology collaborative initiative. Ann Rheum Dis 2015; 74: 17991807, DOI: 10.1136/annrheumdis-2015-207492.

15. Narváez J, Clavaguera MT, Nolla-Solé JM, et al. Lack of association between infection and onset of PMR. J Rheumatol 2000; 27: 953-957.

16. Peris $P$. Polymyalgia rheumatica is not seasonal in pattern and is unrelated to parvovirus B19 infection. J Rheumatol 2003; 30: 2624-2626.

17. Mackie SL, Pease CT, Fukuba E, et al. Whole-body MRI of patients with polymyalgia rheumatica identifies a distinct subset with complete patient-reported response to glucocorticoids. Ann Rheum Dis 2015; 74: 2188-2192, DOI: 10.1136/ annrheumdis-2015-207395.

18. Green DJ, Muller S, Mallen CD, Hider SL. Fatigue as a precursor to polymyalgia rheumatica: an explorative retrospective 